\title{
Domestic Violence Against Women and HIV Vulnerability in Nigeria
}

\author{
Abayomi Samuel Oyekale \\ Department of Agricultural Economics and Extension, North-West \\ University Mafikeng Campus, Mmabatho 2735 South Africa. \\ asoyekale@gmail.com
}

\section{Doi:10.5901/mjss.2014.v5n20p190}

\begin{abstract}
This paper analyzed the impact of domestic violence on HIV vulnerability using the 2008 Demographic and Health Survey (DHS) data. Fuzzy set method was used to construct indices of HIV vulnerability and its correlates were determined by Tobit regression. It was found that among the selected HIV vulnerability attributes, the number of other wives contributed the most (10.30 percent) to HIV vulnerability indices, while North Central and South-South zones had the highest average HIV vulnerability of 0.0669 and 0.0633 , respectively. At the state level, Niger, Enugu and Nasarawa states recorded the highest average HIV vulnerability indices of $0.0889,0.0879$ and 0.0864 . respectively. Also, the most reported domestic violence against women were violation of women's right to ask for the use of condom in sexual relationships (68.32 percent) and lack of power to refuse sex (44.92 percent). The Tobit regression showed that HIV vulnerability was significantly promoted $(p<0.05)$ by majority of the included domestic violence variables in addition to husbands' smoking habit, consumption of alcohol, number of wives, and ignorance about HIV. Access to media (newspaper, radio and television) and wife's years of education significantly reduced HIV vulnerability $(p<0.05)$. It was inter alia noted that within some socio-cultural norms, programmes and policies to advocate for enforcement of women's rights in sexual and marital issues are needed.
\end{abstract}

Keywords: domestic violence, HIV, vulnerability, sexual behavior, Nigeria

\section{Introduction}

In 1981, an immune system weakening disease was first diagnosed among some homosexuals in the United States of America (USA). After a series of worry and anxiety among health workers because new cases were frequently reported, the Centre for Disease Control (CDC) coined an acronym "Acquired Immune Deficiency Syndrome - AIDS" to describe the disease in September 1982 (MWMR Weekly, 1982).Although with a very controversial continent of origin, AIDS is now a dreaded disease for which curative means are yet to be known. This conclusion is coming more than thirty years after being first diagnosed. The sad aspect of the story is that within a very short period of time, HIV had gathered such a monumental speed to have surpassed several previously dreaded diseases in popularity. This is due to its exceptionally severe morbidity with diverse symptoms and a very low probability of being cured. These facts have not been annulled by recently reported cases of "functional cures" of some HIV positive patients (Feratu, 2013).

Global estimates of people living with HIV and AIDS show that sub-Saharan Africa (SSA) bears more than 60 percent of the burdens that are associated with the disease. In 2006, it was estimated that 33.2 million people in the world were living with HIV virus (UNAIDS and WHO, 2007). In 2011, the number had increased to 34 millions. Out of these, 17.2 million were men, 16.8 million were women and 3.4 million were less than 15 years. From about 2.2 million people that died of AIDS in 2005, introduction of antiretroviral drugs seem to be slowing down AIDS-related mortality which reduced to 1.8 million in 2010. It should also be noted that by the physiological structure of their reproductive organ, vulnerability of women and girls is higher than their male counterparts (Pan-American Health Organization, 2007). Similarly, feminization of AIDS in SSA had been strengthened by poverty, with infection rate among young women (15-19 years old) being significantly higher than for young boys of the same age group (World Bank, 2007).

However, health policy makers and researchers have reached a consensus that since no known curative method for HIV\&AIDS presently exists, initiatives to prevent its transmission will go a long way in addressing it. Efforts have been concentrated on reducing people's vulnerability, which can be expressed as practices with specific socio-cultural contexts that can subject a segment of the population to HIV infection. In Nigeria, some previous studies have emphasized some socio-cultural practices and sex-related behaviours that promote spatial distribution of HIV\&AIDS \{Family Health International (FHI), 2000; National Population Commission (NPC), 1999; 2003; Feyisetan and Pebley, 1989; Federal Office of Statistics, 1990\}. Some case studies from different parts of Nigeria have identified large sexual behaviors that 
are anchored by different networks of premarital and extramarital affairs \{Orubuloye et al, 1991; 1995; National Agency for the Control of AIDS (NACA), 2005; Ogbuagu and Charles, 1993\}. These studies highlighted different socio-economic and cultural contexts that encourage risky sexual networking and some spatial variations exist.

Given that the primary medium of HIV transmission is unprotected sexual intercourse or exchange of body fluids through wounds, behaviour change on matters related to sex had been seriously emphasized in order to reduce transmission rates. Therefore, the use of condom for every casual sexual activities, refusal to take unscreened blood, faithfulness to one sexual partner, non-sharing of injection needles and sterilization of any sharp objects that are shared among several people are among the precautionary measures that individuals have been enjoined are to take in order to address the problem.

In Africa, among the causes of HIV vulnerability is gender inequality, which manifests as powerlessness of women in taking critical decisions about domestic or secular issues that affect them. Women are particularly vulnerable to sexual insurgencies that often culminate into rape, assaults and other forms of victimization. This is often aggravated by men's uncontrolled sexual drives, which may lead to subtle exploitation of house maids, illegitimate demand for sex in exchange for marks in colleges and higher institutions of learning, request for sexual gratification by prospective employers or bosses and exchange of sex for any other favours (WHO, 2011). Poverty often aggravates women's vulnerability and in some instances, innocent girls have been lured and trafficked to distant cities and countries where they eventually work as commercial sex workers.

Within marriage relationships, dominance of men often subjects women to sub-ordinate positions. This is sometimes the case even where the children get better treatments. Therefore, marriage contracts are never immunity against exposure to domestic violence. Specifically, domestic violence against women in some marriage relationships are clearly attesting to predominance of socio-economic inequality and existence of some cultural norms that obviously infringe on women's fundamental human rights. This can also increase HIV vulnerability due to several risk factors that emanate from gender-related imbalances within the ambient of sexual relationships among couples (Desai, 2005).

Domestic violence among women often results in reproductive problems through teenage pregnancy, unwanted pregnancies, abortion, and infection with HIV and other Sexually Transmitted Diseases (STDs) (Mboya et al, 2012). There are empirical evidences from research on the association between HIV and AIDS and domestic violence. Some researchers in the U.S. and South Africa have found some positive association between HIVIAIDS and domestic violence (Suzanne et al, 2000, Kristin et al, 2004). In Tanzania, Betron and Doggett (2008) and Suzanne et al (2000) noted that in 2001, majority of women that were living with HIV and AIDS had one time or the other suffered domestic violence from their current partners.

Specifically, violence against women manifests through forceful sexual relationship which may cause abrasions that may provide avenue for HIV transmission (UNAIDS, 2004). Although some differences exist in incidences of domestic violence across geographical regions of the world, World Health Organization (2002) indicated that one out of four women may experience sexual violence. Dunkle et al (2004) found some association between HIV vulnerability and exposure to violence from husbands or intimate partners, male dominance in marital relationships and rape of children in Soweto, South Africa. Also, in Tanzania, Maman et al (2002) found that HIV positive women had higher exposure to domestic violence than their HIV-negative counterparts.

\section{Materials and Methods}

\subsection{The data}

The Nigeria's Demographic and Health Survey (DHS) data for 2008 were used in this study. The choice of the data was informed by availability of comprehensive information on HIV and AIDS related issues, with direct and exhaustive probes into critical issues of domestic violence. Specifically, the data were those coded in the SPSS data file as the couple recode file (NGCR51FL) which was downloaded after receiving official permission from the data administrators (http://www.measuredhs.com/data/dataset/Nigeria_Standard-DHS_2008.cfm?Flag =1). Although DHS data for 2008 were collected from 34070 households that were selected following some probability based sampling procedures, the couple recode file consists of information from 8731 couples. Comprehensive details about the sampling procedures had been provided by National Population Commission (NPC) (2009). 


\subsection{Analytical Model}

\subsubsection{Constructing Indices of HIV Vulnerability: The Fuzzy Set Approach}

Fuzzy set approach had been widely used for data aggregation. Originally proposed by Zadeh (1964), this approach produces indices in the range of zero and one. The aggregation method operates by first identifying some attributes that have been adjudged to be of utmost importance in explaining the phenomenon under study. Thereafter, a range between zero (0) and one (1) is to be defined for each attribute based on the understanding that vulnerability reaches the climax as the index approaches one (1) and the minimum level at zero (0). In this study, indices of HIV vulnerability were computed the following attributes: injection needle not new (yes $=1,0$ otherwise), wife's number of unions (more than one $=1$ and 0 otherwise), husband not at home (yes =1, 0 otherwise), number of other wives (more than one $=1$ and 0 otherwise), husband's number of unions (more than one $=1$ and 0 otherwise), husband has other women (yes $=1,0$ otherwise), husband can have sex with other women (yes =1, 0 otherwise), ignorant of HIV (yes =1, 0 otherwise), wife had STD in the last 12 months (yes =1, 0 otherwise), husband's alcohol consumption last time had sex (yes =1, 0 otherwise), lifetime sexual partners (more than one $=1$ and 0 otherwise), wife had genital sore (yes $=1,0$ otherwise), wife had genital discharges (yes =1, 0 otherwise), husband had STD in the last 12 months (yes =1, 0 otherwise), husband had genital sore (yes $=1,0$ otherwise), husband had genital discharge (yes $=1,0$ otherwise), number other than wife had sex with in the last 12 months (one or more $=1,0$ otherwise), could not get condoms (yes =1, 0 otherwise), never tested for HIV (yes $=1,0$ otherwise), wife's alcohol consumption last time had sex (yes $=1,0$ otherwise), last partner not wife (yes $=1,0$ otherwise) and paid for sex in 12 months' ago (yes =1, 0 otherwise).

HIV vulnerability indices of a couple ${ }^{\mu_{B}}\left(a_{i}\right)$, can defined as the weighted average of $x_{i j}$,

$$
\mu_{B}\left(a_{i}\right)=\sum_{j=1}^{m} x_{i j} w_{j} / \sum_{j=1}^{m} w_{j}
$$

$w_{i}$ is the weight attached to the $j$-th attribute. Deprivation with respect to $X_{j}$ is measured by the weight $w_{j}$. It is an inverse function of the degree of deprivation and the smaller the number of couples and the amount of their deprivation, the greater the weight. In practice, a weight that fulfills the above had been proposed by Cerioli and Zani (1990). This can be expressed as:

$$
w_{j}=\log \left[\sum_{i=1}^{n} g\left(a_{i}\right) / \sum_{i=1}^{n} x_{i j} g\left(a_{i}\right)\right] \geq 0
$$

It should be observed that the weight wis an inverse function of the average degree of deprivation in the population based on the given indicator. The arbitrariness in this weight had been somehow reduced by using its logarithmic function. Ideally, $\mathrm{g}\left(\mathrm{a}_{\mathrm{i}}\right) / \sum_{i=1}^{n} g\left(a_{i}\right)>0$ and $\mathrm{g}\left(\mathrm{a}_{\mathrm{i}}\right) / \sum_{i=1}^{n} g\left(a_{i}\right)$ is the relative frequency represented by the sample observation ai in the total population. Therefore, when everybody possesses an attribute or nobody has it, the attribute should be removed because it is of no relevance.

The fuzzy set approach allows the decomposition of the vulnerability indices based on the contributions of each indicator or attribute. The vulnerability of the population $\mu_{\mathrm{B}}$ is simply obtained as a weighted average of the vulnerability of the $i$-th couple $\mu_{B}\left(a_{i}\right)$

$$
\mu_{B}=\sum_{i=1}^{n} \mu_{B}\left(a_{i}\right) g\left(a_{i}\right) / \sum_{i=1}^{n} g\left(a_{i}\right) .
$$

Similarly,

$$
\mu_{B}\left(X_{j}\right)=\sum_{i=1}^{n} x_{i j} g(a) / \sum_{i=1}^{n} g\left(a_{i}\right)
$$
weight $\mathrm{w}_{\mathrm{j}}$.

In this way it is possible to decompose vulnerability of the population $\mu_{B}$ as the weighted average of $\mu_{B}\left(X_{j}\right)$, with

$$
\mu_{B}=\sum_{i=1}^{n} \mu_{B}\left(a_{i}\right) g\left(a_{i}\right) / \sum_{i=1}^{n} g\left(a_{i}\right)=\sum_{j=i}^{m} \mu_{B}\left(X_{j}\right) w_{j} / \sum_{j=1}^{m} w_{j}
$$

\subsection{Tobit Regression Model}

The Tobit regression method was used to determine the socio-economic factors influencing HIV vulnerability. This is due to the nature of the data. We censored the data at zero (0). The estimated Tobit model can be stated as: 


$$
\mu_{\beta}=\varpi+\lambda_{j} \sum_{j=1}^{n} X_{j}+e_{i}
$$

Where $\varpi$ is the constant term and $\lambda_{j} s$ are the parameters. The error term is denoted as $e_{i}$. The included explanatory variables $\left(X_{j}\right)$ are wife has no right to ask for condom if husband has STDs (yes $=1,0$ otherwise), wife cannot refuse sex (yes $=1,0$ otherwise), wife cannot ask partner to use condom (yes $=1,0$ otherwise), Husband said wife not justified to ask husband to use condom if he has STD (yes $=1,0$ otherwise),husband has right to: use force for unwanted sex (yes $=1,0$ otherwise), wife beating justified if she refuses to have sex with him (yes $=1,0$ otherwise), husband accuses her of unfaithfulness (yes $=1,0$ otherwise), anyone forced respondent to perform sexual acts (yes $=1,0$ otherwise), justifies domestic violence if wife fails to prepare food on time (yes $=1,0$ otherwise), justifies domestic violence if wife refuses to have another children (yes $=1,0$ otherwise), ever had bruises because of husband's act (yes = 1, 0 otherwise), ever physically hurt husband when he was not hurting you (yes $=1,0$ otherwise), can HIV and AIDS be cured (yes $=1,0$ otherwise), partner drinks alcohol (yes $=1,0$ otherwise), household size, age of wife, husband smokes cigarette (yes $=1,0$ otherwise), north central zone (yes $=1,0$ otherwise), North-East zone (yes $=1,0$ otherwise), NorthWest zone (yes = 1, 0 otherwise), South East zone (yes = 1, 0 otherwise), South-South zone (yes = 1, 0 otherwise), urban residence (yes $=1,0$ otherwise), number of wives, wife's years of education, Islamic religion (yes $=1,0$ otherwise), wife reading newspaper (yes $=1,0$ otherwise), wife listening to radio (yes $=1,0$ otherwise), wife watching television (yes $=1,0$ otherwise), husband's years of education, household head age, husband reading newspaper (yes $=1,0$ otherwise), husband listening to radio (yes $=1,0$ otherwise) and husband watching television (yes =1, 0 otherwise).

\section{Results and Discussions}

\subsection{Indicator of HIV vulnerability}

Table 1 shows the weights of the twenty two attributes that were selected for constructing indices of HIV vulnerability. Based on fuzzy specification, the summation of all the weights of the attributes was 27.06 . The attribute with highest weight was paid for sex in the past twelve months (2.24). This was followed by husband had genital sore (2.02). The attributes with the lowest weights were never tested for HIV $(0.08)$ and husband had other women (0.14). Figure 1 shows the distribution of the HIV vulnerability indices using kernel density. It reveals that HIV vulnerability indices were positively skewed (majority have values $\leq 0.10$ ). However, it was concluded that because HIV transmission can be transmitted with the lowest vulnerability, majority of the couples were vulnerable while only 0.88 percent had zero vulnerability index.

The contributions of the attributes to overall HIV vulnerability are also presented in table 1 . The table shows that number of wives contributed the highest proportion (10.30 percent) to HIV vulnerability. The practice of polygamy by cultural norms or religious teaching can fuel HIV due to multiple sexual engagements of the man with several women that may not exercise complete faithfully in their marriages. In some states in Nigeria, multiple sexual engagements may be formalized as spouse sharing (Osagbemi and Jegede, 2001; Osagbemi et al, 2007), wife inheritance and secret sexual involvements with concubines and girl friends (Ekanem et al, 2005) Other attributes that contributed to HIV vulnerability were inability to get condom (9.42 percent), number of lifetime sexual partners ( 9.25 percent) and ignorant of HIV ( 8.83 percent). It should be noted that although inability to get condom may constitute serious HIV vulnerability in Nigeria, especially in the rural areas where this may combine with ignorance and other risky sexual behavior to fuel HIV transmission. The least contributors to HIV vulnerability were paid for sex in the last twelve months (0.87 percent), husband had genital sore (1.22 percent) and injection needles not new (1.40 percent).

Table 1: Selected Attributes' Weights and Contributions to HIV Vulnerability

\begin{tabular}{lccc}
\hline \multicolumn{1}{c}{ Attributes } & Weights & Absolute Contributions & Relative Contributions \\
\hline Number of other wives & 0.49 & 0.0059 & 10.30 \\
Could not get condoms & 0.28 & 0.0054 & 9.42 \\
Lifetime sexual partners & 0.27 & 0.0053 & 9.25 \\
Ignorant of HIV & 0.77 & 0.0048 & 8.38 \\
Husband's number of unions & 0.9 & 0.0042 & 7.33 \\
Wife's number of unions & 0.92 & 0.0041 & 7.16 \\
Husband has other women & 0.14 & 0.0038 & 6.63 \\
Husband can have sex with other women & 1.08 & 0.0033 & 5.76 \\
Last partner not wife & 1.15 & 0.003 & 5.24 \\
Number other than wife had sex in the last 12 months women & 1.23 & 0.0027 & 4.71
\end{tabular}




Never tested for HIV
Wife had genital discharges
Husband's alcohol consumption last time had sex
Wife had genital sore
Wife had STD in the last 12 months
Husband had genital discharge
Wife's alcohol consumption last time had sex
Husband not at home
Husband had STD in the last 12 months
Injection needle not new
Husband had genital sore
Paid for sex in 12 months' ago
Total

Never tested for HIV 0.08

$\begin{array}{lc}0.0025 & 4.36 \\ 0.0019 & 3.32 \\ 0.0016 & 2.79 \\ 0.0014 & 2.44 \\ 0.0012 & 2.09 \\ 0.0012 & 2.09 \\ 0.0011 & 1.92 \\ 0.0011 & 1.92 \\ 0.0008 & 1.40 \\ 0.0008 & 1.40 \\ 0.0007 & 1.22 \\ 0.0005 & 0.87 \\ 0.0573 & 100.00\end{array}$

Source: Author's computations for Nigeria 2008 DHS data.

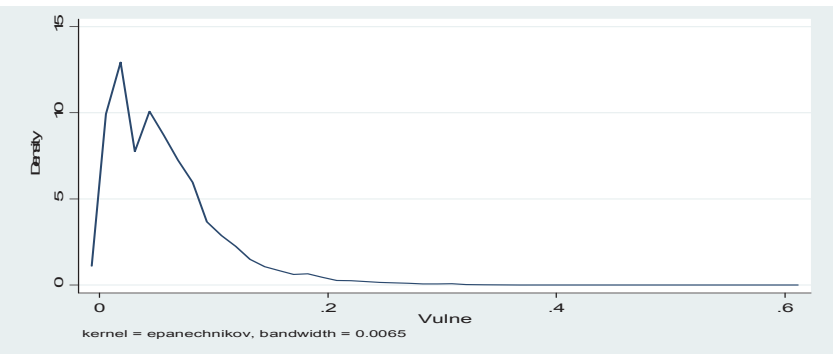

Figure 1: Kernel density distribution of HIV vulnerability indices in Nigeria

\subsection{Distribution of HIV vulnerability indices}

Table 2 shows the distribution of the HIV vulnerability indices across the states and geo-political zones in the rural and urban areas. It reveals that in the combined data, while average overall vulnerability index was 0.0573 , couples that were resident in urban areas had lower average HIV vulnerability index $(0.0465)$ than those from rural areas $(0.0613)$. Also, those from South-West zone had the lowest average HIV vulnerability index $(0.0458)$, while South-South zone had the highest (0.0633). In urban areas, similar trend was observed where South-West had the lowest average vulnerability $(0.0384)$ and South-South had the highest $(0.0608)$. It should be emphasized that HIV vulnerability indices in the rural areas were generally higher where North-West zone had the smallest value $(0.0529)$ and North-Central had the highest value (0.0736). These results can be considered in line with the 2010 national sentinel survey. Official statistics indicate that rural areas' vulnerability to HIV has not generally translated into HIV infection since rural Nigeria generally had lower HIV prevalence rates than urban areas in the 2010 survey. The zonal level vulnerability can be compared with HIV prevalence rates where North-West had the lowest value of 2.7 percent that is followed by South-West with 3.7 percent (Federal Ministry of Health, 2010).

Across the states in the North-West zone, the combined analysis shows that Zamfara state had the highest vulnerability $(0.0560)$, while Kano had the lowest value $(0.0470)$. In rural and urban areas in the North-West zone, Zamfara and Jigawa states had highest vulnerability indices of 0.0581 and 0.0585 respectively. It should be noted that while rural areas in Zamfara state had the highest average HIV vulnerability in the North-West zone, residents in her urban areas had the lowest average HIV vulnerability (0.0291). Table 2 also shows that in the combined data, the states in the North-East zone with highest HIV vulnerability index were Yobe and Taraba with 0.0731 and 0.0701 respectively. Yobe state clearly had highest HIV vulnerability with highest values in the rural $(0.0755)$ and urban $(0.0665)$ areas. Also, HIV vulnerability is higher in all the states in the rural areas than those in urban. In the North-West zone, the combined data results show that Niger, Nasarawa and Benue states had highest average vulnerability indices of $0.0889,0.0864$ and 0.0824 , respectively. Except for Enugu state that had average HIV vulnerability index of 0.0879 , these values were obviously among the highest that were recorded for the Nigerian states. Couples that were resident in urban and rural areas in Niger state had the highest HIV vulnerability indices of 0.0781 and 0.0889 , respectively. 
In South-West zone, Ogun state had the highest HIV vulnerability index (0.0621) in the combined data. Also, in the urban areas, Ogun state had the highest vulnerability index of 0.0674 while Ondo state had the highest vulnerability $(0.0648)$ in rural areas. Also, in results for combined data in South-South zone, Balyesa and Delta states had the highest HIV vulnerability indices of 0.0723 and 0.0718 , respectively. In urban areas, Rivers state had the highest average HIV vulnerability index of 0.0743 , while Delta recorded the highest value of 0.764 in rural areas. In the South-East zone, Enugu state had highest HIV vulnerability index (0.0879) in the combined data. Also, Enugu state recorded the highest HIV vulnerability indices of 0.0946 and 0.0853 in the urban and rural areas respectively. The average HIV vulnerability index of Enugu state in the urban areas was the highest computed across all the states and zones.

Table 2: Average HIV Vulnerability Indices in Urban and Rural Nigeria

\begin{tabular}{|c|c|c|c|c|c|c|c|c|c|}
\hline \multirow{2}{*}{ States/Zones } & \multicolumn{3}{|c|}{ All Households } & \multicolumn{3}{|c|}{ Urban Households } & \multicolumn{3}{|c|}{ Rural Households } \\
\hline & Freq & Mean & StdDev & Freq & Mean & StdDev & Freq & Mean & StdDev \\
\hline North West & 2,561 & 0.0515 & 0.0413 & 416 & 0.0442 & 0.0436 & 2,145 & 0.0529 & 0.0407 \\
\hline Jigawa & 348 & 0.0513 & 0.0339 & 28 & 0.0585 & 0.0360 & 320 & 0.0506 & 0.0337 \\
\hline Kaduna & 363 & 0.0479 & 0.0464 & 107 & 0.0337 & 0.0299 & 256 & 0.0538 & 0.0506 \\
\hline Kano & 406 & 0.0470 & 0.0421 & 83 & 0.0502 & 0.0570 & 323 & 0.0462 & 0.0373 \\
\hline Katsina & 493 & 0.0507 & 0.0336 & 80 & 0.0490 & 0.0445 & 413 & 0.0510 & 0.0311 \\
\hline Kebbi & 390 & 0.0551 & 0.0519 & 61 & 0.0447 & 0.0392 & 329 & 0.0570 & 0.0538 \\
\hline Sokoto & 292 & 0.0548 & 0.0382 & 37 & 0.0478 & 0.0541 & 255 & 0.0558 & 0.0353 \\
\hline Zamfara & 269 & 0.0560 & 0.0394 & 20 & 0.0291 & 0.0253 & 249 & 0.0581 & 0.0396 \\
\hline North East & 2,002 & 0.0630 & 0.0486 & 413 & 0.0527 & 0.0446 & 1,589 & 0.0656 & 0.0493 \\
\hline Adamawa & 278 & 0.0569 & 0.0496 & 44 & 0.0444 & 0.0310 & 234 & 0.0593 & 0.0521 \\
\hline Bauchi & 386 & 0.0575 & 0.0445 & 91 & 0.0447 & 0.0362 & 295 & 0.0615 & 0.0461 \\
\hline Borno & 334 & 0.0624 & 0.0455 & 97 & 0.0547 & 0.0564 & 237 & 0.0655 & 0.0399 \\
\hline Gombe & 356 & 0.0580 & 0.0464 & 52 & 0.0565 & 0.0584 & 304 & 0.0583 & 0.0441 \\
\hline Taraba & 300 & 0.0701 & 0.0664 & 40 & 0.0398 & 0.0271 & 260 & 0.0748 & 0.0694 \\
\hline Yobe & 348 & 0.0732 & 0.0352 & 89 & 0.0665 & 0.0366 & 259 & 0.0755 & 0.0345 \\
\hline North Central & 1,623 & 0.0669 & 0.0571 & 418 & 0.0474 & 0.0523 & 1,205 & 0.0736 & 0.0571 \\
\hline Benue & 197 & 0.0824 & 0.0643 & 22 & 0.0448 & 0.0391 & 175 & 0.0871 & 0.0654 \\
\hline Kogi & 177 & 0.0520 & 0.0491 & 49 & 0.0566 & 0.0594 & 128 & 0.0503 & 0.0447 \\
\hline Kwara & 240 & 0.0645 & 0.0380 & 76 & 0.0517 & 0.0381 & 164 & 0.0704 & 0.0366 \\
\hline Nasarawa & 225 & 0.0864 & 0.0659 & 22 & 0.0792 & 0.0544 & 203 & 0.0871 & 0.0671 \\
\hline Niger & 316 & 0.0889 & 0.0623 & 52 & 0.0887 & 0.0781 & 264 & 0.0889 & 0.0588 \\
\hline Plateau & 249 & 0.0518 & 0.0468 & 46 & 0.0419 & 0.0492 & 203 & 0.0541 & 0.0461 \\
\hline Abuja & 219 & 0.0328 & 0.0389 & 151 & 0.0253 & 0.0322 & 68 & 0.0495 & 0.0469 \\
\hline South West & 1,137 & 0.0458 & 0.0432 & 625 & 0.0384 & 0.0408 & 512 & 0.0549 & 0.0444 \\
\hline Ekiti & 161 & 0.0470 & 0.0415 & 64 & 0.0323 & 0.0323 & 97 & 0.0567 & 0.0442 \\
\hline Lagos & 288 & 0.0391 & 0.0452 & 265 & 0.0374 & 0.0436 & 23 & 0.0586 & 0.0591 \\
\hline Ogun & 142 & 0.0621 & 0.0488 & 36 & 0.0674 & 0.0470 & 106 & 0.0603 & 0.0496 \\
\hline Ondo & 157 & 0.0531 & 0.0475 & 73 & 0.0396 & 0.0403 & 84 & 0.0648 & 0.0504 \\
\hline Osun & 210 & 0.0355 & 0.0341 & 128 & 0.0332 & 0.0336 & 82 & 0.0393 & 0.0347 \\
\hline Oyo & 179 & 0.0485 & 0.0369 & 59 & 0.0415 & 0.0406 & 120 & 0.0519 & 0.0346 \\
\hline South South & 850 & 0.0633 & 0.0579 & 250 & 0.0608 & 0.0667 & 600 & 0.0644 & 0.0539 \\
\hline Akwalbom & 140 & 0.0580 & 0.0569 & 8 & 0.0706 & 0.0977 & 132 & 0.0573 & 0.0540 \\
\hline Bayelsa & 168 & 0.0723 & 0.0534 & 45 & 0.0654 & 0.0614 & 123 & 0.0748 & 0.0502 \\
\hline Cross River & 133 & 0.0633 & 0.0536 & 31 & 0.0526 & 0.0452 & 102 & 0.0666 & 0.0556 \\
\hline Delta & 133 & 0.0718 & 0.0671 & 57 & 0.0656 & 0.0634 & 76 & 0.0764 & 0.0698 \\
\hline Edo & 152 & 0.0502 & 0.0386 & 72 & 0.0498 & 0.0417 & 80 & 0.0506 & 0.0359 \\
\hline Rivers & 124 & 0.0642 & 0.0739 & 37 & 0.0743 & 0.1109 & 87 & 0.0599 & 0.0510 \\
\hline South East & 558 & 0.0506 & 0.0483 & 226 & 0.0447 & 0.0476 & 332 & 0.0546 & 0.0484 \\
\hline Abia & 120 & 0.0504 & 0.0516 & 62 & 0.0534 & 0.0575 & 58 & 0.0472 & 0.0447 \\
\hline Anambra & 112 & 0.0302 & 0.0337 & 85 & 0.0264 & 0.0291 & 27 & 0.0419 & 0.0437 \\
\hline Ebonyi & 153 & 0.0578 & 0.0464 & 37 & 0.0519 & 0.0365 & 116 & 0.0597 & 0.0491 \\
\hline Enugu & 77 & 0.0879 & 0.0555 & 21 & 0.0946 & 0.0550 & 56 & 0.0853 & 0.0560 \\
\hline Imo & 96 & 0.0331 & 0.0332 & 21 & 0.0302 & 0.0428 & 75 & 0.0339 & 0.0303 \\
\hline Total & 8,731 & 0.0573 & 0.0492 & 2,348 & 0.0465 & 0.0485 & 6,383 & 0.0613 & 0.0489 \\
\hline
\end{tabular}

Source: Author's computations from 2008 DHS data. 


\subsection{Different Forms of Domestic Violence Against Women}

The survey probed into the different forms of domestic violence that women experienced (table 3 ). It reveals that across the zones, 43.06 percent and 42.29 percent of the respondents from North-East and South-East indicated that the wife had no right to ask husband to use condom if he had any STDs. On this, across the states, Yobe (77.01 percent), Ebonyi (67.97 percent) and Zamfara (63.20 percent) reported the highest percentages. Also, 60.64 percent and 60.14 percent of the women from North-West and North-East zones reported that they had no right to refuse sex. Many of the states from these zones specifically Sokoto (83.56 percent), Kano (77.09 percent), Borno (75.75 percent) and Yobe (72.70 percent) had highest percentages.

Another form of domestic violence that was probed into was indications by the husband whether the wife had the right to request use of condom in sexual relationship. In the North-East zone, 81.87 percent of the husbands indicated that their wives had no right to request use of condoms in sexual relationships. This was the highest computed percentage in all the states. Next to this were North-West and South-East zones with 79.46 percent and 64.87 percent, respectively. Across the states, Sokoto, Yobe and Zamfara had 94.18 percent, 93.39 percent and 91.82 percents respectively indicating that wives had no right to request for use of condom. However, while many of the men responded contrary to request by wife for condom use, quite reasonably fewer of them indicated that the wife could not mandate them to use condom if it is medically confirmed that they have any STDs. Specifically, across the zones, 24.37 percent and 23.94 percent of the husband from South-East and North-West zones indicated that they could not be mandated by their wives to use condom even if they were infected with any STDs. These were also the highest percentages across the zones. Similarly, Zamfara, Enugu Jigawa, Yobe and Ebonyi states recorded the highest percentages with 62.83 percent, 49.35 percent, 48.56 percent, 45.69 percent and 43.79 percent, respectively. However, states like Osun (0.00 percent), Edo (1.32 percent), Kaduna (2.48 percent), Bayelsa (3.57 percent) and Anambra (3.57) had very low percentages.

Some wives reported that their husbands ever forced them for unwanted sex. In the zones, North-East and NorthCentral had highest percentages with 20.18 percent and 6.84 percent, respectively. At state level, Yobe, Borno and Nassarawa states had highest percentages with 52.87 percent, 29.64 percent and 23.11 percent, respectively. However, no woman reported to have been forced for sex in Oyo and Lagos states. Similarly, some women indicated that they were beaten because of refusal to have sex with their husbands. In North-East zone, 27.57 percent of the women indicated this. Highest percentages were had in Yobe, Borno and Nassarawa states with 46.84, 44.31 and 41.78, respectively. No woman indicated to have been beaten because of sex in Edo state. Also, some women were accused of unfaithfulness by their husbands. The highest proportions were in the North-Central and South-South zones with 14.85 percent and 13.29 percent respectively.

Some women reported that they had been previously forced to have sex by some men. In South-East and SouthSouth, 5.38 percent and 3.65 percent respectively reported this. Across the states, Benue, Enugu and Abia states had the highest percentages of $13.20,9.09$ and 6.67, respectively. Some women indicated that domestic violence would be justified if they did not prepare food on time. In the zones, North-East and North Central had 28.97 percent and 26.31 percent, respectively. Bauchi, Plateau, Ebonyi, Gombe, Taraba states 50.78 percent, 42.17 percent, 39.22 percent, 38.20 percent, 37.67 percent, respectively. Also, some women indicated that their husbands could beat them due to unyielding to their demand for more children. The highest responses for this were from Taraba, Bauchi, Borno and Plateau states with 46.00 percent, 43.26 percent, 42.51 percent and 40.56 percent, respectively. Similarly, some husbands had bruised their wives in some violent circumstances. Respondents from Rivers state (16.13 percent), Akwa lbom state (12.14 percent) and Edo state (11.18 percent) reported the highest proportion percentages. However, confrontational attempts that had hurt the husbands had been made by some women. Highest percentages were reported in Akwa Ibom state (14.29), Delta state (6.02), Benue state (5.08) and Abia state (5.00). 
Table 3: Percentage distributions of reported domestic violence across states and zones in Nigeria

\begin{tabular}{|c|c|c|c|c|c|c|c|c|c|c|c|c|c|}
\hline \multirow[b]{2}{*}{ State/Zone } & \multirow[b]{2}{*}{ Freq } & \multicolumn{4}{|c|}{ Wife has no right to } & \multicolumn{7}{|c|}{ Husband said he has right to } & She \\
\hline & & $\begin{array}{c}\text { ask for } \\
\text { condom due } \\
\text { to STD }\end{array}$ & $\begin{array}{l}\text { refuse } \\
\text { Sex }\end{array}$ & $\begin{array}{l}\text { ask for } \\
\text { condom }\end{array}$ & $\begin{array}{l}\text { ask for condom due } \\
\text { to STD }\end{array}$ & $\begin{array}{l}\text { force her } \\
\text { for sex }\end{array}$ & $\begin{array}{c}\text { beat her for } \\
\text { sex }\end{array}$ & $\begin{array}{c}\text { accuse } \\
\text { her }\end{array}$ & $\begin{array}{l}\text { forcedfor } \\
\text { sex }\end{array}$ & $\begin{array}{c}\text { beat her } \\
\text { (food) }\end{array}$ & $\begin{array}{c}\text { Beat her -demand more } \\
\text { children }\end{array}$ & $\begin{array}{l}\text { bruise by } \\
\text { husband }\end{array}$ & $\begin{array}{l}\text { hurts the } \\
\text { husband }\end{array}$ \\
\hline North West & 2,561 & 36.43 & 60.64 & 79.46 & 23.94 & 6.25 & 11.91 & 6.40 & 1.95 & 15.74 & 10.82 & 1.17 & 0.23 \\
\hline Jigawa & 348 & 57.18 & 44.54 & 83.05 & 48.56 & 3.74 & 8.91 & 15.80 & 0.57 & 35.92 & 22.99 & 0.57 & 0.00 \\
\hline Kaduna & 363 & 8.82 & 65.01 & 64.19 & 2.48 & 4.96 & 4.96 & 6.89 & 1.93 & 27.82 & 25.34 & 1.93 & 0.55 \\
\hline Kano & 406 & 42.36 & 77.09 & 80.05 & 7.88 & 1.97 & 3.45 & 1.97 & 0.99 & 12.56 & 9.85 & 0.00 & 0.00 \\
\hline Katsina & 493 & 31.03 & 41.58 & 81.54 & 20.49 & 12.58 & 9.94 & 1.83 & 0.61 & 10.34 & 4.26 & 0.20 & 0.20 \\
\hline Kebbi & 390 & 35.64 & 69.23 & 67.69 & 30.00 & 6.67 & 25.90 & 15.13 & 5.38 & 5.38 & 9.23 & 2.82 & 0.51 \\
\hline Sokoto & 292 & 23.29 & 83.56 & 94.18 & 5.48 & 8.22 & 20.89 & 0.00 & 1.03 & 18.15 & 2.40 & 0.68 & 0.34 \\
\hline Zamfara & 269 & 63.20 & 48.33 & 91.82 & 62.83 & 3.35 & 11.52 & 2.97 & 3.72 & 0.37 & 0.37 & 2.60 & 0.00 \\
\hline North East & 2,002 & 43.06 & 60.14 & 81.87 & 19.33 & 20.18 & 27.57 & 10.84 & 2.90 & 28.97 & 28.97 & 2.70 & 1.10 \\
\hline Adamawa & 278 & 38.85 & 62.59 & 87.77 & 6.47 & 12.23 & 25.90 & 5.04 & 1.80 & 2.16 & 2.16 & 2.52 & 1.08 \\
\hline Bauchi & 386 & 53.89 & 51.04 & 80.05 & 8.55 & 11.40 & 18.39 & 10.88 & 3.37 & 50.78 & 43.26 & 1.30 & 0.52 \\
\hline Borno & 334 & 25.15 & 75.75 & 82.04 & 30.54 & 29.64 & 44.31 & 17.07 & 5.69 & 29.34 & 42.51 & 4.49 & 1.80 \\
\hline Gombe & 356 & 35.67 & 64.89 & 69.94 & 5.06 & 6.46 & 19.66 & 4.21 & 0.28 & 38.20 & 27.81 & 0.84 & 0.84 \\
\hline Taraba & 300 & 22.33 & 32.00 & 79.33 & 19.00 & 6.67 & 9.33 & 28.33 & 6.00 & 37.67 & 46.00 & 6.33 & 2.67 \\
\hline Yobe & 348 & 77.01 & 72.70 & 93.39 & 45.69 & 52.87 & 46.84 & 1.15 & 0.57 & 8.91 & 8.05 & 1.44 & 0.00 \\
\hline $\begin{array}{l}\text { North } \\
\text { Central }\end{array}$ & 1,623 & 32.10 & 37.95 & 62.05 & 20.02 & 6.84 & 14.97 & 14.85 & 2.71 & 26.31 & 21.93 & 3.39 & 1.60 \\
\hline Benue & 197 & 40.61 & 11.17 & 70.05 & 15.74 & 2.03 & 15.74 & 26.40 & 13.20 & 35.53 & 21.32 & 4.57 & 5.08 \\
\hline Kogi & 177 & 22.03 & 31.64 & 62.71 & 15.82 & 5.65 & 12.99 & 7.34 & 1.13 & 30.51 & 25.42 & 2.82 & 1.69 \\
\hline Kwara & 240 & 57.08 & 54.17 & 69.58 & 34.17 & 0.83 & 0.83 & 8.33 & 0.83 & 16.67 & 2.08 & 3.75 & 0.42 \\
\hline Nasarawa & 225 & 47.56 & 59.11 & 72.44 & 5.78 & 23.11 & 41.78 & 19.11 & 1.33 & 15.11 & 22.22 & 5.78 & 2.67 \\
\hline Niger & 316 & 18.67 & 47.47 & 46.84 & 37.66 & 5.70 & 12.97 & 22.15 & 1.27 & 37.66 & 34.18 & 1.58 & 0.63 \\
\hline Plateau & 249 & 21.29 & 30.92 & 67.47 & 11.24 & 8.84 & 20.08 & 16.47 & 2.41 & 42.17 & 40.56 & 5.62 & 1.20 \\
\hline Abuja & 219 & 21.00 & 21.92 & 51.14 & 10.96 & 1.37 & 0.91 & 0.91 & 0.46 & 2.28 & 2.28 & 0.00 & 0.46 \\
\hline South West & 1,137 & 14.42 & 16.97 & 43.45 & 15.13 & 0.70 & 6.07 & 8.36 & 0.97 & 14.07 & 6.07 & 2.90 & 1.41 \\
\hline Ekiti & 161 & 19.25 & 16.77 & 57.14 & 42.24 & 1.24 & 1.86 & 7.45 & 0.00 & 16.77 & 8.70 & 1.86 & 1.24 \\
\hline Lagos & 288 & 7.64 & 16.67 & 33.68 & 17.01 & 0.00 & 5.21 & 9.03 & 3.13 & 2.78 & 0.69 & 3.47 & 3.47 \\
\hline Ogun & 142 & 16.90 & 22.54 & 47.18 & 4.23 & 1.41 & 7.04 & 9.15 & 0.70 & 33.80 & 10.56 & 2.82 & 1.41 \\
\hline Ondo & 157 & 24.84 & 15.29 & 40.13 & 19.11 & 1.91 & 1.27 & 10.19 & 0.00 & 20.38 & 11.46 & 5.10 & 0.00 \\
\hline Osun & 210 & 9.52 & 19.52 & 43.33 & 0.00 & 0.48 & 12.86 & 5.24 & 0.00 & 8.10 & 4.29 & 1.43 & 0.48 \\
\hline Oyo & 179 & 15.64 & 11.73 & 46.93 & 10.61 & 0.00 & 6.70 & 9.50 & 0.56 & 15.64 & 6.15 & 2.79 & 0.56 \\
\hline South South & 850 & 20.71 & 23.53 & 50.35 & 8.47 & 3.65 & 6.24 & 13.29 & 3.65 & 16.59 & 7.53 & 8.71 & 6.12 \\
\hline Akwalbom & 140 & 7.86 & 26.43 & 51.43 & 10.00 & 7.86 & 3.57 & 14.29 & 5.00 & 15.00 & 3.57 & 12.14 & 14.29 \\
\hline Bayelsa & 168 & 12.50 & 17.86 & 36.90 & 3.57 & 4.17 & 9.52 & 17.86 & 4.17 & 10.12 & 4.76 & 8.33 & 4.76 \\
\hline Cross River & 133 & 32.33 & 34.59 & 43.61 & 6.77 & 3.76 & 9.77 & 19.55 & 3.76 & 33.83 & 1.50 & 2.26 & 4.51 \\
\hline Delta & 133 & 44.36 & 26.32 & 54.89 & 21.05 & 1.50 & 7.52 & 7.52 & 0.75 & 10.53 & 3.01 & 2.26 & 6.02 \\
\hline Edo & 152 & 9.87 & 16.45 & 65.79 & 1.32 & 1.97 & 0.00 & 3.95 & 3.95 & 13.16 & 15.79 & 11.18 & 4.61 \\
\hline Rivers & 124 & 21.77 & 21.77 & 50.81 & 10.48 & 2.42 & 7.26 & 16.94 & 4.03 & 19.35 & 16.94 & 16.13 & 2.42 \\
\hline South East & 558 & 42.29 & 27.96 & 64.87 & 24.37 & 3.23 & 6.45 & 10.57 & 5.38 & 18.10 & 10.22 & 4.84 & 3.23 \\
\hline Abia & 120 & 24.17 & 13.33 & 53.33 & 12.50 & 4.17 & 4.17 & 8.33 & 6.67 & 10.00 & 6.67 & 6.67 & 5.00 \\
\hline Anambra & 112 & 32.14 & 36.61 & 57.14 & 3.57 & 2.68 & 1.79 & 9.82 & 2.68 & 2.68 & 0.89 & 1.79 & 3.57 \\
\hline Ebonyi & 153 & 67.97 & 33.33 & 76.47 & 43.79 & 1.31 & 11.76 & 11.76 & 5.88 & 39.22 & 22.88 & 5.88 & 2.61 \\
\hline Enugu & 77 & 40.26 & 41.56 & 57.14 & 49.35 & 9.09 & 11.69 & 15.58 & 9.09 & 31.17 & 16.88 & 1.30 & 2.60 \\
\hline Imo & 96 & 37.50 & 16.67 & 76.04 & 12.50 & 1.04 & 2.08 & 8.33 & 3.13 & 2.08 & 0.00 & 7.29 & 2.08 \\
\hline Total & 8,731 & 33.12 & 44.92 & 68.32 & 19.53 & 8.38 & 14.41 & 10.18 & 2.57 & 20.75 & 16.07 & 3.13 & 1.60 \\
\hline
\end{tabular}

Source: Author's computations from 2008 DHS data

\section{Linking HIV Vulnerability to Domestic Violence and some other Socio-Economic Factors}

The relationships between domestic violence and HIV vulnerability was explored using Tobit regression. The results are presented in table 4 which reveals that the model produced a good fit of the data given the statistical significance of the Likelihood Ratio Chi-Square $(p<0.01)$. Many of the parameters of the variables that were included to capture domestic violence were all statistically significant $(p<0.05)$. Specifically, the variable wife has no right to ask for condom if husband had STDs is with positive parameter $(0.0034718)(p<0.01)$. Also, another variable that was credited to men saying that the woman has not justification to request they use condom if they are infected with STDs also has positive parameter $(0.0032574)$ which is statistically significant $(p<0.01)$. These results are expected because if the husband has STDs and have unprotected sexual relationship with the woman, the disease will be transmitted. STDs is one of the major avenues for HIV transmission because it may cause sore on the reproductive organ that may act as door for HIV virus. However, the parameter of wife cannot ask partner to use condom $(-0.0033927)$ is statistically significance $(p<0.01)$. This parameter shows that vulnerability is lower among those that responded yes to that question. It also goes to show that the respondents, by reason of low vulnerability did not any reason why they should be mandated to use condom.

Also, the parameter of the wife cannot refuse sex variable is also with positive sign $(0.003809)(p<0.01)$. Also, the parameter of husband has right to use force for unwanted sex $(0.0189035)$ is statistically significant $(p<0.01)$, while that 
for beating of the wife is justified if she refuses to have sex with the husband $(0.0090828)$ is statistically significant $(p<0.01)$. These results imply that vulnerability to HIV is higher among those that could not refuse sex or that can be forcefully engaged in sexual activities. Inability to refuse sex implies that even if a wife realizes that it is not safe to do so, she cannot say no. This will increase HIV vulnerability.

Furthermore, the parameter of husband accused her of unfaithfulness $(0.0038273)$ is statistically significant $(p<0.01)$. This is expected because when the wife is accused of unfaithfulness in marriage relationship, it can lead to abandonment of the wife by the husband who if he is having many wives will shift to those other wives for sexual relationships. However, if he only has one wife, he may begin to explore sexual satisfaction from other women outside at a very high risk of contracting HIV.

Some women indicated that someone had forcefully carried out sexual activities with them before. The variable is with a parameter $(0.0095033)$ which is statistically significant $(p<0.01)$. This is expected because being raped increases vulnerability to HIV because it is an unwanted sexual activity that is full of several risks. For instance, the rapist may be HIV positive or infected with STDs. This presupposes that HIV transmission will be rapid in an environment where raping is common practice.

Some variables to capture domestic violence that are not sex related were also included. These variables are violence as a result of wife's failure to prepare food on time, bruise on the wife because of husband's actions and wife physically hurting the wife when the husband was hurting her with parameters of $0.0030458,0.0084308$ and 0,0148431 respectively. These parameters are all statistically significant $(p<0.05)$. The results imply that couples with some other domestic unrest are also with higher vulnerability to HIV. These can be explained from the fact that when the home is not settled, there may come some tendencies for indulgence in extra-marital issues that can promote HIV. In some instance, staying outside the home into very late at night can be triggered by such domestic violence, which often predicates into other vices like drunkenness, smoking and womanizing.

The parameters of partner drinks alcohols $(0.0143814)$ and smoking $(0.0134956)$ are statistically significant $(p<0.05)$. These results imply that being a smoker and alcohol favorite increase HIV vulnerability. Precisely, alcoholism and smoking are habits that often predispose men to being exposed to bad gangs. In many instances, regular attendance at bar parlours often engender some misconducts of keeping concubines or girl friends, and sometimes visiting commercial sex workers. The implication of all these is very high vulnerability to HIV.

The parameter of North-Central is statistically significant $(p<0.05)$. This implies that the constant term of couples from this zone is statistically higher by 0.0081304 than those from South-West zone (base). However, the parameters of North-West zone $(-0.0007680)$ and South-South zone $(0.0119493)$ are statistically significant $(p<0.01)$. These show that autonomous HIV vulnerability indices in North-Central and South-South are respectively lower and higher than what obtains in South-West zone. Quite well, there is regional disparity in HIV vulnerability in Nigeria due to cultural differences and some critical marital issues defined by religious beliefs.

Residents in urban areas have significantly lower $(p<0.01)$ autonomous HIV vulnerability judging by the parameter of residence in urban areas $(-0.0051163)$. In many instances, vulnerability to HIV is anchored by illiteracy, which is rampart in rural areas. Rural people are also likely to hold some cultural values like polygamy, male domination in marital issues and abject suppression of women. However, because of poverty, domestic violence that often engender higher HIV vulnerability cannot be ignored.

The number of wives parameter is statistically significant $(p<0.01)$. This implies that if the number of wives increases by one, HIV vulnerability of couple increases by 0.0137795 . This is expected because polygamy can breed HIV because of multiple sexual activities that would be performed by the man.

Furthermore, the parameter of the number of women's years of education is statistically significant $(p<0.05)$. This implies that if the years of education increases by one unit, HIV vulnerability will decrease by 0.0006984 . This is expected because education is supposed to enhance understanding of individuals about behavioural issues surrounding HIV transmission. This finding can be directly linked with the parameter of can HIV be cured which has positive parameter and statistically significant $(p<0.01)$. The parameter implies that autonomous HIV vulnerability of those with wrong knowledge about curability is higher than those with right knowledge.

The issue of education can also directly impact ability of the couples to explore information from different media. The parameters of access of women to newspapers, radio and television are statistically significant $(p<0.05)$ and all with negative sign. However, only the parameter of reading newspaper by men is statistically significant $(p<0.05)$. These results are expected because media programmes are meant to educate couples on HIV vulnerability. 
Table 4: Tobit regression results of the determinants of HIV vulnerability

\begin{tabular}{|c|c|c|c|c|}
\hline Variables & Coefficient & Std. Error & t-statistic & $P>|t|$ \\
\hline Wife has no right to ask for condom if husband has STDs & .0034718 & .0011554 & 3.00 & 0.003 \\
\hline Wife cannot refuse sex & .003809 & .0011373 & 3.35 & 0.001 \\
\hline Wife cannot ask partner to use condom & -.0033927 & .0012439 & -2.73 & 0.006 \\
\hline Husband said wife not justified to ask husband to use condom if he has STD & .0032574 & .001294 & 2.52 & 0.012 \\
\hline Husband has right to: use force for unwanted sex & .0189035 & .001983 & 9.53 & 0.000 \\
\hline Wife beating justified if she refuses to have sex with him & .0090828 & .0015613 & 5.82 & 0.000 \\
\hline Husband accuses her of unfaithfulness & .0038273 & .0016914 & 2.26 & 0.024 \\
\hline Anyone forced respondent to perform sexual acts & .0095033 & .0031698 & 3.00 & 0.003 \\
\hline Justifies domestic violence: Wife fails to prepare food on time & .0030458 & .001539 & 1.98 & 0.048 \\
\hline Justifies domestic violence: Wife refuses to have another children & .0025784 & .0017286 & 1.49 & 0.136 \\
\hline Ever had bruises because of husband's act & .0084308 & .0029881 & 2.82 & 0.005 \\
\hline Ever physically hurt husband when he was not hurting you & .0148431 & .0041067 & 3.61 & 0.000 \\
\hline Can HIV and AIDS be cured? & .0058222 & .0017648 & 3.30 & 0.001 \\
\hline Partner drinks alcohol & .0143814 & .0016905 & 8.51 & 0.000 \\
\hline Age of wife & .0001424 & .0000817 & 1.74 & 0.081 \\
\hline Husband smokes cigarette & .0134956 & .0017296 & 7.80 & 0.000 \\
\hline North central zone & .0081304 & .0019082 & 4.26 & 0.000 \\
\hline North-East zone & -.0019088 & .0020727 & -0.92 & 0.357 \\
\hline North-West zone & -.0076804 & .0019518 & -3.94 & 0.000 \\
\hline South East zone & -.0018799 & .0024482 & -0.77 & 0.443 \\
\hline South-South zone & .0119493 & .0021551 & 5.54 & 0.000 \\
\hline Urban residence & -.0051163 & .0013097 & -3.91 & 0.000 \\
\hline Number of wives & .0137795 & .0009991 & 13.79 & 0.000 \\
\hline Wife's years of education & -.0006984 & .0002522 & -2.77 & 0.006 \\
\hline Islamic religion & .0001666 & .0001594 & 1.05 & 0.296 \\
\hline Wife reading newspaper & -.0078122 & .0016927 & -4.62 & 0.000 \\
\hline Wife listening to radio & -.0023741 & .0011964 & -1.98 & 0.047 \\
\hline Wife watching television & -.0056699 & .0014619 & -3.88 & 0.000 \\
\hline Husband's years of education & -.0002261 & .0002324 & -0.97 & 0.331 \\
\hline Household head age & .0003173 & .0000703 & 4.52 & 0.000 \\
\hline Husband reading newspaper & -.002556 & .0012964 & -1.97 & 0.049 \\
\hline Husband listening to radio & .0012468 & .0015461 & 0.81 & 0.420 \\
\hline Husband watching television & .0001086 & .0013296 & 0.08 & 0.935 \\
\hline Constant & .0222149 & .003474 & 6.39 & 0.000 \\
\hline Sigma & .045869 & .0003492 & & \\
\hline LR chi2(34) 1357.39*** Log likelihood & & & & \\
\hline
\end{tabular}

\section{Conclusion}

HIV vulnerability is directly motivated by risky behaviours that can be strengthened by prevalence of domestic violence. The cultural norms and socio-economic problems that often engender sophisticated interactions between domestic violence and HIV vulnerability portends a policy challenge to most policy makers in developing countries. This becomes a critical challenge given the structure of sexual behavior and gender imbalance notions that are often held in high esteem. This paper, taking the argument from a gender imbalance approach, analyzed the impact of domestic violence on vulnerability of Nigerian couples to HIV. The key findings have identified some key areas where policy interventions can assist in reducing HIV. It was found in accordance with some previous studies that South-South Nigeria and NorthCentral had the highest HIV vulnerability indices. Although there is general need to ensure proper orientation of all Nigerians on matters that promote HIV transmission, special attention should be given to South-South and North-Central zones (and most especially the states with highest HIV vulnerability indices) in order to understand the socio-cultural drivers and address them. Also, notable among the major drivers of HIV vulnerability is polygamy. It is important to devise some ways of reaching homes that are polygamous and ensure that adequate education on the best safety measures against HIV is given to them.

There were differences in the types of domestic violence that women experienced across the zones and states in Nigeria. However, it was clear that matters related to the right of women to refuse sex and demand for use of condom were disdained by many respondents from northern parts of Nigeria. This may have resulted from cultural and religious 
obligations that undermine women's rights in sexual relationships. Government needs to ensure that programmes and policies to advocate for enforcement of women's rights in sex-related issues are adequately promulgated and implemented.

It is also important to emphasize that in the parametric results, many of the parameters of domestic violence are positively related to HIV vulnerability. This calls for interventions to redress family conflicts and ensure harmony and unity. This can be address through media programmes. This is vital because the results also show that engagement of couples with some media programmes through reading of newspapers, listening to radio and watching television reduced vulnerability to HIV. However, media houses should also be strengthened to transmit programmes on HIV and sex education. This will ensure that people are adequately enlightened on matters that pertain to their vulnerability to HIV. This can be directly linked to the parameter women's education which indicated that HIV vulnerability reduces with higher education. Promotion of girl child education cannot be downplayed as a way of reducing HIV vulnerability. This is vital because educated women will be able to exercise their rights on sex-related matters within the household.

Finally, alcoholism and smoking were found to significantly increase HIV vulnerability. It is therefore important to ensure that media programmes to enlighten smokers and alcohol consumers on the adverse consequences of their behavior are in place. Government's existing policies on smoking prohibition in certain places should be implemented and efforts to restrict sale of alcohol should strengthened. It is also important that in this effort, youths are adequately targeted to ensure that they do not grow to step into the shoes wore by their fathers.

\section{References}

Betron, M. and E. Doggett 2008. A Review of Risk Factors and Promising Interventions.2008 http://pdf.usaid.gov/pdf_docs/ PNADN851.pdf.Accessed 8 December 2012.

Cerioli A. and S. Zani. 1990. A fuzzy approach to the measurement of poverty", In: Dagum C, Zenga M. eds., Income and wealth distribution, inequality and poverty., Berlin: Springer Verlag, , 272-284.

Desai, S. 2005. HIV and AIDS and Domestic Violence: Intersections in the Lives of Married Women in India

Dunkle, K. L., R.K. Jewkes, H.C. Brown, G.E. Gray, J.A. McIntyre, S.D. Harlow 2004. Gender-based violence, relationship power, and risk of HIV infection in women attending antenatal clinics in South Africa The Lancet.

Ekanem, E.E., B.M. Afolabi, A.O. Nuga, and S.B. Adebajo 2005. Sexual Behaviour, HIV-Related Knowledge and Condom Use by Intracity Commercial Bus Drivers and Motor Park Attendants in Lagos, Nigeria. African Journal of Reproductive Health 9(1):7887.

Family Health International (FHI). HIVIAIDS Behavioural Surveillance Survey: Nigeria 2000. Report and Data Sheet . http://www.fhi.org/en/hivaids/pub/survreports/bssnigeria 2000.htm, 2000.

Federal Ministry of Health (2010). 2010 National HIV Sero-prevalence Sentinel Survey. Department of Public Health, National AIDS/STI Control Programme

Federal Office of Statistics. Nigeria Demographic and Health Survey. 1990.

Feratu, S. (2013).Two cases of a "functional cure" for HIVIAIDS. Internet file retrieved on 25 th April 2013 from http://www.wsws.org/en/ articles/2013/03/30/aids-m30.html

Feyisetan B and Pebley AR. Premarital Sexuality in Urban Nigeria. Studies in Family Planning, 20(6):343\{354, 1989.

Kristin, D., J. Rachel, B. Heather, G. Glenda, M. James, H. SiobãiN. 2004. Gender based violence, relationship power, and risk of HIV infection in women attending antenatal clinics in South Africa. Lancet. 363(9419):1415-1421.

Maman, S., J. Mbwambo, N. Hogan, G. Kilonzo. 2002. HIV-positive women report more lifetime partner violence: findings from a voluntary counseling and testing clinic in Dar Es Salaam, Tanzania. American Journal of Public Health

.Mboya, B., F. Temu, B. Awadhi, Z. Ngware, E. Ndyetabura, G. Kiondo and J. Maridadi 2012. Access to HIV prevention services among gender based violence survivors in Tanzania. Pan Afr Med J. 2012; 13(Supp 1): 5.

MMWR Weekly 1982. Current trends update on Acquired Immune Deficiency Syndrome (AIDS) - United States. September 24, 31(37); 507-508, 513-514.

National Agency for the Control of AIDS, 2005. Abuja. Nigeria UNGASS Report.

National Population Commission, Abuja. 1999. Nigeria Demographic and Health Survey. Federal Republic of Nigeria.

National Population Commission, Abuja. 2003. Nigeria Demographic and Health Survey. Federal Republic of Nigeria.

National Population Commission, Abuja. 2009. Nigeria Demographic and Health Survey. Federal Republic of Nigeria.

Ogbuagu SC and Charles JO. Survey of Sexual networking in Calabar. Health Transition Review, 3:105\{119, 1993.

Orubuloye I.O, J. Caldwell, and P. Caldwell 1991. Sexual networking in Ekiti District of Nigeria. Studies in Family Planning, 22(2):61\{73, 1991.

Orubuloye I.O, J. Caldwell, and P. Caldwell 1995. The cultural, social and attitudinal context of male sexual behaviour in urban southwest Nigeria. Health Transition Review, 5:207\{222, 1995

Osagbemi M.O., and A.S. Jegede 2001. Spouse-sharing practice and reproductive health promotion among Okun people of Nigeria. African Population Studies, 16(2):91\{116, 2001.

Osagbemi M.O., B. Joseph, A.A. Adepetu, A.O. Nyong, and A.S. Jegede. 2007. Culture and HIV/AIDS in Africa: Promoting Reproductive 
Health in Light of Spouse-Sharing Practice among Okun People, Nigeria. World Health and Population,

Pan-American Health Organization, "Gender and HIVIAIDS," Women, Health and Development Programme, Fact Sheet, June 2007.

Suzanne, M., C. Jacquelyn, S. Michael, G. Andrea 2000. The intersections of HIV and violence: directions for future research and interventions. Soc Sci Med. 50(4):459-78.

UNAIDS 2004. 2004 Report on Global Trends in the HIVIAIDS Epidemic. UNAIDS / UNAIDS (Joint United Nations Programme on HIVIAIDS) (2004).

UNAIDS/WHO, AIDS Epidemic Update, December 2006, UNAIDS, Geneva, 2007, p. 3.

World Bank, Global Monitoring Report, World Bank, Washington DC, 2007, pp. 74-75.

World Health Organization (WHO) 2002. Public health has a crucial role to play in addressing the causes and consequences of violence.

World Health Organization 2011. Media center fact sheet on violence against women. http://www.who.int/mediacentre/factsheets /fs239/en/.Accessed 5 August 2012.

Zadeh L.A. 1965. Fuzzy set. Information and Control, 8,338-53. 